\title{
Linear Dynamics Finite Element Simulation Using Virtual Parts in Catia v $5^{\text {TM }}$
}

\author{
Hamoon Ramezani, M.A.Sc., Nader G. Zamani, Ph.D. P.Eng. \\ University of Windsor, Canada, ramezanh@uwindsor.ca, zamani@uwindsor.ca
}

\begin{abstract}
The origin of the virtual parts in Catia $v 5$ is traced back to the RBE elements (Rigid Bar Elements) in the NASTRAN program. The focus of this paper is to explore the functionalities of such elements in linear dynamic problems utilizing Catia v5. Several FEA benchmarks or case studies employing Rigid virtual part and Rigid Spring virtual part under commonly applied boundary conditions are provided. The advantages and disadvantages of these tools are discussed to help the software users choose the right strategy in modeling their structure based on the requirements and goals in mind.
\end{abstract}

Keywords—Rigid virtual part, Rigid Spring virtual part, finite element analysis, linear dynamic analysis, modal superposition technique

\section{INTRODUCTION}

In the early 1960s, "Rigid" elements were introduced in the NASTRAN program to decrease the cost of computation which is a critical issue in FEA simulations. Virtual parts are the modified versions of those elements in the Catia v5 finite element software [1]. The virtual part toolbar in Catia v5 includes five different icons, namely, Rigid virtual part, Rigid Spring virtual part, Smooth virtual part, Smooth Spring virtual part, and Contact virtual part. Reference [2] included a detailed discussion of the concepts and differences of the Rigid and Smooth virtual part. This paper however discusses only the Rigid and the Rigid Spring varieties.

In publication [3], linear static analysis utilizing virtual parts were discussed. Important basic information about the virtual parts are presented in that publication, including the differences between "Rigid", "Rigid Spring", and "Smooth" virtual parts. Furthermore, three case studies to demonstrate the use of such tools under different loads were presented. These are the common axial, torsional and bending forces. The Catia generated stresses are verified against analytical solutions, when available, and the "Fully 3D" FEA models otherwise.

Since, linear dynamics is based on the concept of modal superposition, the authors investigated the behavior of virtual parts and their role in modal analysis, in an earlier publication [4]. The first section of that paper is a detailed description of the origin and concept of virtual parts including RBE, RBE2, RBE3 in NASTRAN, and their relationship to Rigid virtual part and Rigid Spring virtual part in Catia v5. Moreover, it outlines how to transfer the applied force and moment and calculate the displacement of the "Handler" point which is also discussed in detail in reference [5]. The main feature in [4] is numerous case studies dealing with virtual parts for frequency calculations of a simple geometry, under common loading conditions and restraints. The first 3 natural frequencies of each case study were compared with existing analytical solutions or performing fully 3D FEA modeling without using virtual parts. These are important steps in linear dynamics analysis because of the role of the modal superposition technique. As in the static analysis paper [3], the cases are divided into 3 different categories namely, axial, torsional, and bending deformation under a fixed-free boundary condition. Reference [2] also includes other useful restraints such as fixed-fixed and free-free conditions.

In this presentation, both the transient and steady state (sinusoidal) simulations were conducted. The transient calculation deals with an independent variable which is "time" whereas, in the steady state (Harmonic/sinusoidal) case, the independent variable is the excitation "frequency".

\section{THE CASE STUdIES UNDER CONSIDERATION}

This paper considers eight case studies involving the dynamic axial, bending and torsional forces for a simple part using Rigid virtual part and the Rigid Spring virtual part under a Fixed-Free boundary conditions. The main reason behind simple loading and geometry is to be able to compare the results with analytical solutions. For the case of axial and bending loads, the cross section is square, whereas, for the torsional study, the cross section is circular. The steel material with the Young's modulus E $=200 \mathrm{GPa}$, Poisson's ratio $v=0.266$, and $\rho=7860 \mathrm{~kg} / \mathrm{m}^{3}$ is assumed for all cases. A simple geometry is taken into consideration in the paper in order to prevent distractions due to insignificant details. Considering the geometries shown in Fig. 1, the actual total length of the bar is $L=150 \mathrm{~mm}$. This total length is consisting of two portions namely "Modeled Portion" with the length $L_{M P}=100 \mathrm{~mm}$ and "Virtual Portion" with the length $L_{V P}=50 \mathrm{~mm}$.

When using Rigid Spring virtual part, the stiffness of the resulting spring needs to be calculated as a one-dimensional geometry, under axial, bending, and torsional loading based on elementary strength of material formulas. These are displayed in Fig. 2.

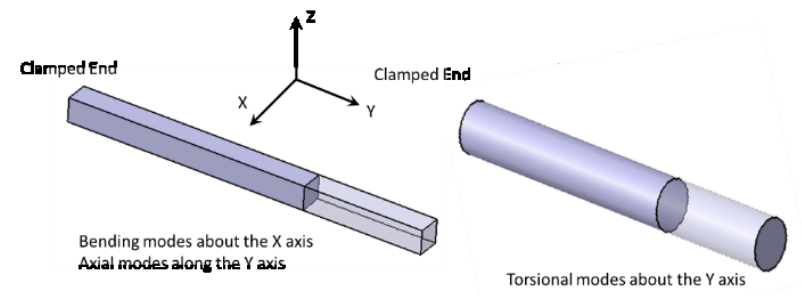

Fig. 1 Geometry and boundary conditions of the case studies considered [2]

Digital Object Identifier (DOI):

http://dx.doi.org/10.18687/LACCEI2019.1.1.8

ISBN: 978-0-9993443-6-1 ISSN: 2414-6390

$17^{\text {th }}$ LACCEI International Multi-Conference for Engineering, Education, and Technology: "Industry, Innovation, And Infrastructure for Sustainable Cities and Communities”, 24-26 July 2019, Jamaica. 


$$
\begin{aligned}
& k_{\text {torsion }}=\frac{G J}{0.5 L_{V P}}, k_{\text {axial }}=\frac{E A}{0.5 L_{V P}}, \\
& k_{\text {bending,translation }}=\frac{3 E I}{\left(0.5 L_{V P}\right)^{3}}, k_{\text {bending,rotation }}=\frac{E I}{0.5 L_{V P}}
\end{aligned}
$$

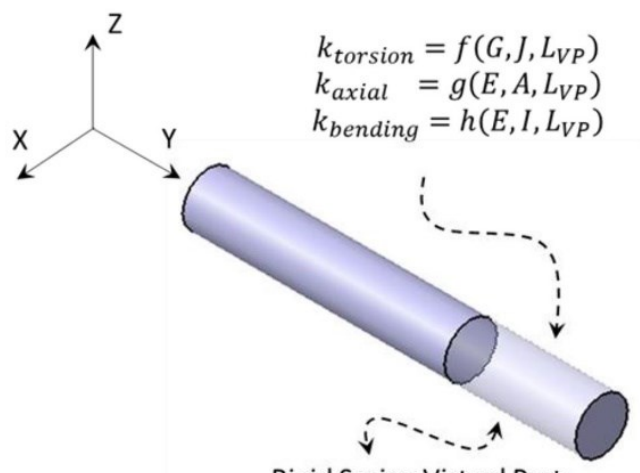

Rigid Spring Virtual Part

Fig. 2 A generic, simplified problem for illustration purposes for the case studies considered

This figure is only for illustration purposes. The variables "G" and "E" are the shear and Young's modulus respectively, whereas, "J" and "I" are the polar and second moment of area. Furthermore, "A" is the cross-sectional area. The relevant stiffnesses are given in Fig. 2. The spring constants can be translational and/or rotational in nature and up to six such values can be inputted in the appropriate dialogue box which is provided in Fig. 3. In more complex parts, these values can be specified by conducting simple experiments in a controlled

\begin{tabular}{|c|c|c|c|}
\hline Rigid Spring Virtual Part & 口 & 回 & $\mathfrak{Z}$ \\
\hline \multicolumn{4}{|c|}{ Name Rigid Spring Virtual Part.1 } \\
\hline \multicolumn{3}{|l|}{ Supports 1 Face } & 为 \\
\hline \multicolumn{4}{|l|}{ Handler 1 Point } \\
\hline \multicolumn{4}{|l|}{ Axis System } \\
\hline Type Global & & & $\checkmark$ \\
\hline \multicolumn{4}{|l|}{$\square$ Display locally } \\
\hline \multicolumn{4}{|c|}{ Translation Stiffness 1 0N_m } \\
\hline \multicolumn{4}{|c|}{ Translation Stiffness 2 ON_m } \\
\hline \multicolumn{4}{|c|}{ Translation Stiffness 3 ON_m } \\
\hline \multicolumn{4}{|c|}{ Rotation Stiffness 1 ONxm_rad } \\
\hline \multicolumn{4}{|c|}{ Rotation Stiffness 2 ONxm_rad } \\
\hline \multicolumn{4}{|c|}{ Rotation Stiffness 3 ONxm_rad } \\
\hline 0 & & 9 & ncel \\
\hline
\end{tabular}
environment [2].

Fig. 3 Rigid Spring Virtual Part dialogue box [3]III. A Clamped Bar With an Applied Force in the Midspan

\section{Case (a), Rigid Spring Virtual Part, Axial Deformation}

The bar depicted in Fig. 4 is under an axial dynamic load of magnitude $\mathrm{F}(\mathrm{t})=1000 \mathrm{~N}$ which is applied in the middle of the bar, $75 \mathrm{~mm}$ away from the clamped end. Instead of modelling the whole part with solid elements, a Rigid Spring virtual part is considered for latter $50 \mathrm{~mm}$ of the bar and placed at the centroid of the "Virtual Portion" as the "Handler" point. Fig. 4 also shows a "Fully 3D FEA" model using solid elements to be employed for comparison purposes.

The axial stiffness of this spring $k_{V P}=\frac{A E}{0.5 L_{V P}}=8 E+8 \mathrm{~N} / \mathrm{m}$ is taken into account in the Rigid Spring virtual part model. This is calculated based on half the length of the virtual part, i.e. $0.5 L_{V P}=25 \mathrm{~mm}$ and inputted in the model. One way to apply a $1000 \mathrm{~N}$ force to the bar is to create two points $\mathrm{A}$ and $\mathrm{B}$ on the side faces of the $150 \mathrm{~mm}$ bar and apply $500 \mathrm{~N}$ at each of these two points. This strategy was followed to apply the load in the desired direction. The mass of the virtual part $m_{V P}=$ $0.0393 \mathrm{~kg}(10 \mathrm{x} 10 \mathrm{~mm}$ square cross section) is calculated based on the density of the material and placed at the handler point of the virtual part for both models.
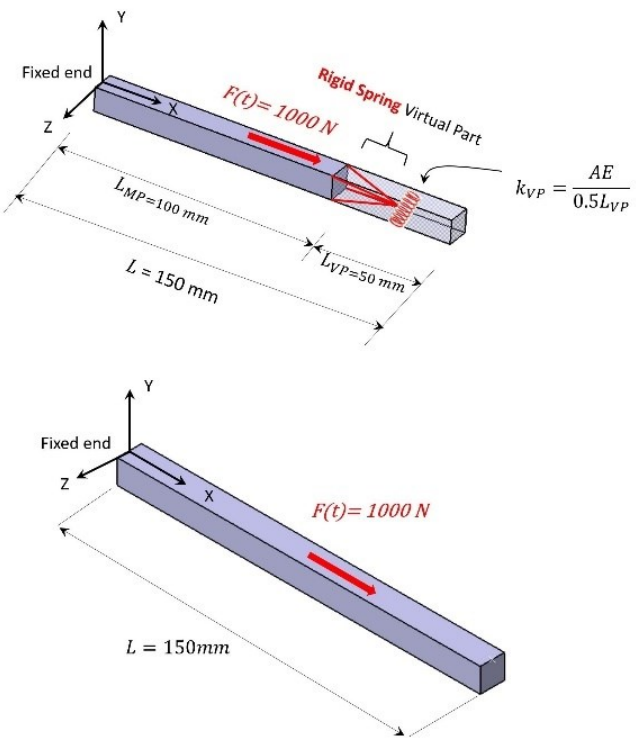

Fig. 4 (a) The Rigid Spring virtual part and (b) The Fully 3D FEA models of the Fixed-Free case under axial dynamic load

The Catia generated X-direction deflection of point A where the force is applied for both models during the first 0.001 seconds are plotted in Fig. 5. As depicted, the Rigid Spring virtual part model is in a good agreement with the "Fully 3D FEA" Model. It means that by using Rigid Spring virtual part instead of solid elements for the latter $50 \mathrm{~mm}$ of the bar, the number of elements is decreased by one third, therefore the cost of computation is decreased significantly but the resut is in reasonable agreement with the full 3D model.

$17^{\text {th }}$ LACCEI International Multi-Conference for Engineering, Education, and Technology: "Industry, Innovation, And Infrastructure for Sustainable Cities and Communities", 24-26 July 2019, Jamaica. 


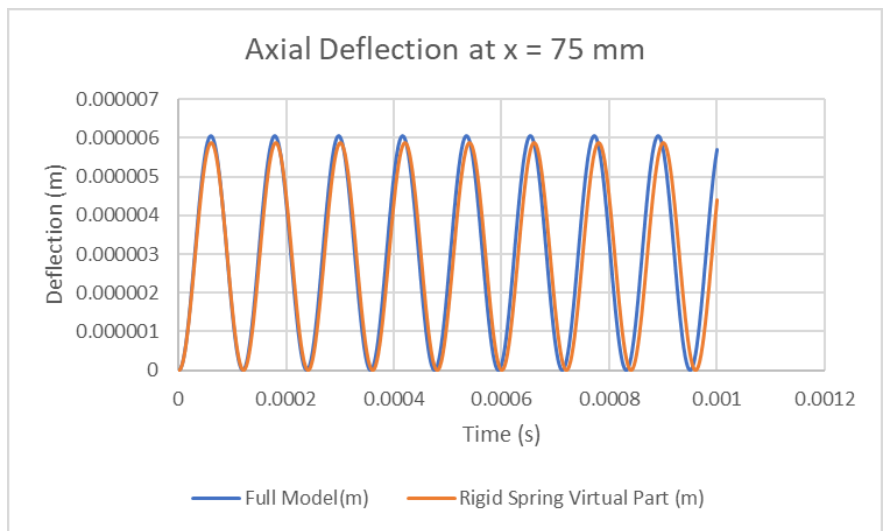

Fig. 5 The axial deflections of the Fixed-Free beam under an axial dynamic force at the middle

Case (b), Rigid Virtual Part, Axial Deformation

This is the same as the case (a) except that a Rigid virtual part (instead of the Rigid Spring) is used for the right $50 \mathrm{~mm}$ portion of the bar shown in Fig. 6. As the latter $50 \mathrm{~mm}$ behaves substantially more rigid in the Rigid virtual part model in comparison to the fully 3D steel model, the "Fully 3D FEA" model is not a good idealization for the Rigid Virtual Part. Therefore, a more appropriate reference finite element model using beam elements only is created in Catia v5.

In this reference model, 20 beam elements are used to replace the first $100 \mathrm{~mm}$ and 10 beam elements to model the end $50 \mathrm{~mm}$ displayed in Fig. 7. The latter $50 \mathrm{~mm}$ of the bar is assumed to be more rigid than the rest of the bar. Therefore, the Young's modulus of the end $50 \mathrm{~mm}$ is 100 times larger than the left $100 \mathrm{~mm}$ of the bar. The multiplier is arbitrarily selected but may warrant some sensitivity analysis. All of these 30 elements have the true $10 \times 10 \mathrm{~mm}$ cross section. The density of the shorter section is as same as steel. For all practical purposes, the shorter section is acting as a rigid bar. The mass of the right $50 \mathrm{~mm}$ section is directly taken into the consideration by using the actual density of steel. This is symbolically shown in Fig. 7 as the 11 lumped masses on this section which incidentally can be misleading.

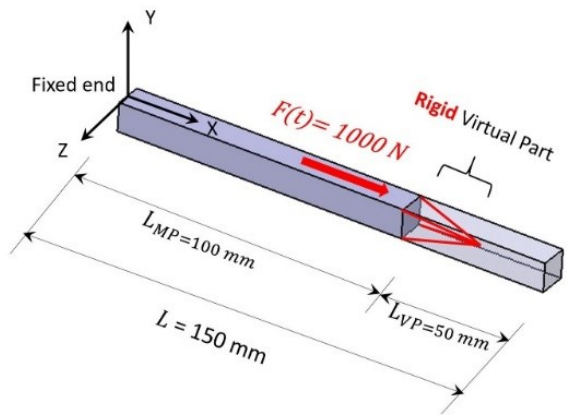

Fig. 6 The Rigid virtual part and the Rigid Spring virtual part models of the Fixed-Free case under axial dynamic load

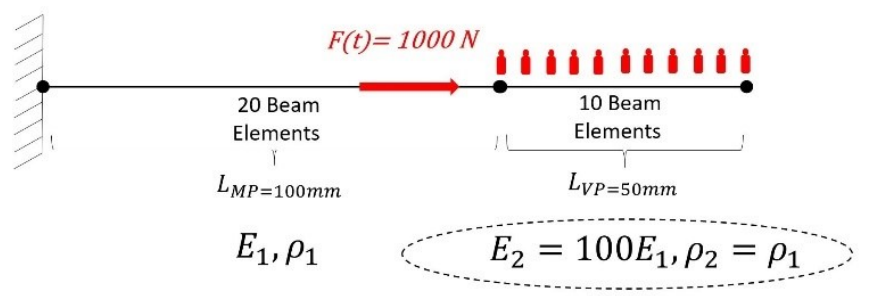

Fig. 7 The reference model for comparison purpose for Rigid virtual part model of the Fixed-Free bar under an axial dynamic force at its middle point [2]

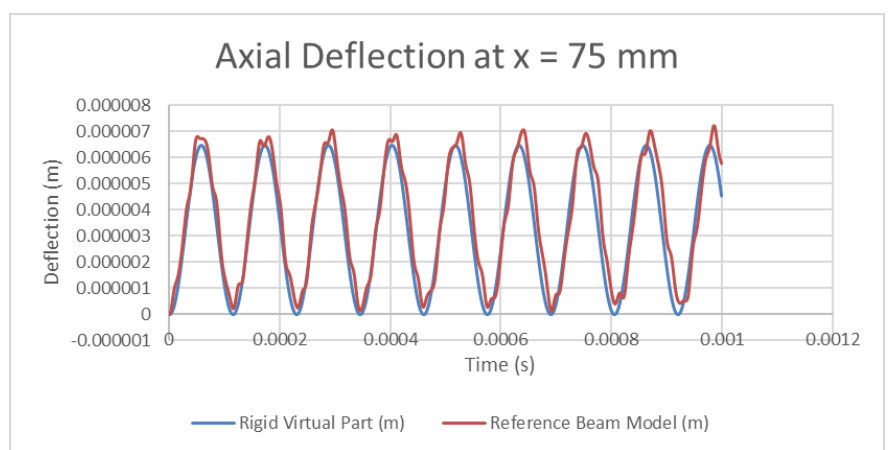

Fig. 8 The axial deflections of the beam under an axial dynamic force at the middle [2]

The axial deflection of the middle point of the Rigid virtual part and the reference model where the dynamic loads are applied are plotted in Fig. 8. The Rigid virtual part model result is in a very good agreement with the reference beam model [2].

\section{Case (c), Rigid Spring Virtual Part, Bending Deformation}

The same bar considered in the previous two cases is under a bending dynamic load $\mathrm{F}(\mathrm{t})=1000 \mathrm{~N}$ at the middle point, $\mathrm{x}=$ $75 \mathrm{~mm}$. As in the axial analysis, the last $50 \mathrm{~mm}$ on the right end of the bar is modeled with both Rigid Spring virtual part and solid elements, as shown in Fig. 9. The mass of the virtual part $m_{V P}=0.0393 \mathrm{~kg}$ based on the density of the material for the virtual portion is placed at the handler point of the Rigid virtual part. It is necessary to calculate the stiffnesses of the virtual portion and take it into account in the Rigid Spring virtual part. As shown in Fig. 2, the translational spring along "Y" axis, $k_{V P, Y}=\frac{3 E I}{(0.5 L V P)^{3}}=3.2 E+7 \mathrm{~N} / \mathrm{m}$ and the rotational spring stiffness about the "Z" axis, $k_{\mathrm{VP}, \theta \mathrm{Z}}=\frac{E I}{0.5 L V P}=6.67 E+$ $3 \mathrm{~N} . \mathrm{m} / \mathrm{rad}$ have been used.

The Catia generated "Y" direction deflection of the middle point of the bar where the force is applied during the first 0.01 seconds are plotted in Fig. 10. The time-dependent deflection of the Rigid Spring virtual part model is in a very good agreement with the "Fully 3D FEA" model. Therefore, the cost of computation is significantly decreased without influencing the result by using a Rigid Spring virtual element instead of a

$17^{\text {th }}$ LACCEI International Multi-Conference for Engineering, Education, and Technology: "Industry, Innovation, And Infrastructure for Sustainable Cities and Communities", 24-26 July 2019, Jamaica. 
$50 \mathrm{~mm}$ Steel continuum bar [2]. In this paper, the metric for computational cost is the numbers of elements.
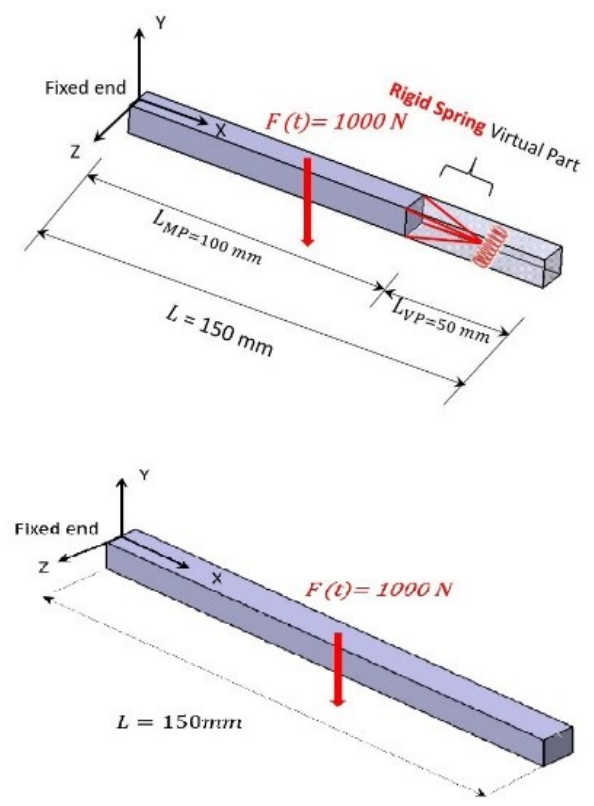

Fig. 9 (a) The Rigid Spring virtual part and (b) The Fully 3D FEA models for the Fixed-Free case under a bending dynamic load at the middle

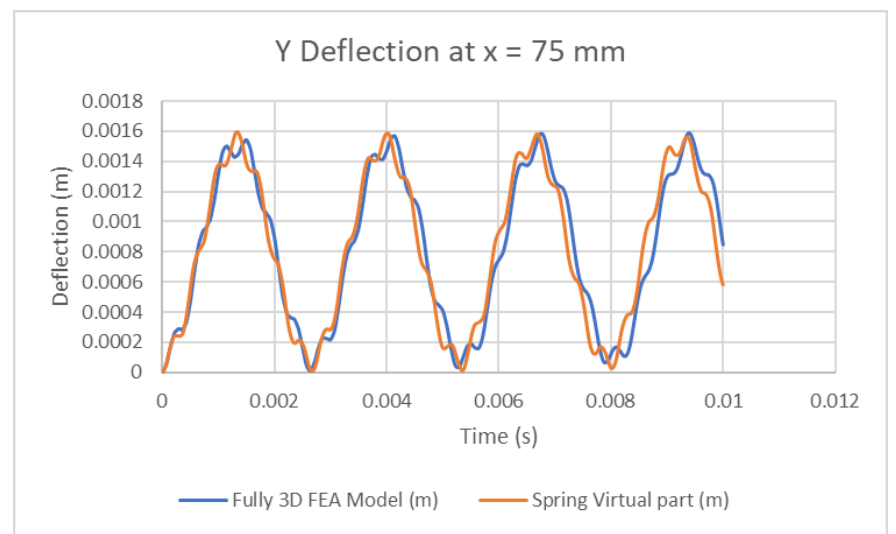

Fig. 10 The bending deflections of the Fixed-Free beam under a bending dynamic force at the middle

\section{Case (d), Rigid Virtual Part, Bending Deformation}

This is the same problem considered in case (c) except that the Rigid virtual part is used for the latter $50 \mathrm{~mm}$ of the bar. Therefore, the last $50 \mathrm{~mm}$ of the bar behaves substantially stiffer than the rest of the bar. Hence, the same reference finite element model using beam elements described in case (b) earlier, is created in Catia v5 for comparison purposes. This situation is depicted in Fig. 11.

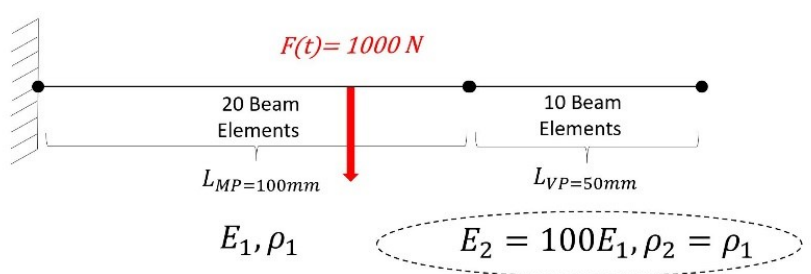

Fig. 11 The reference model for comparison purpose for the case (d)

The bending deflection of the middle node of the Rigid virtual part and the reference model where the dynamic loads are applied are plotted in Fig. 12. The Rigid virtual part model result is in a good agreement with the reference beam model.

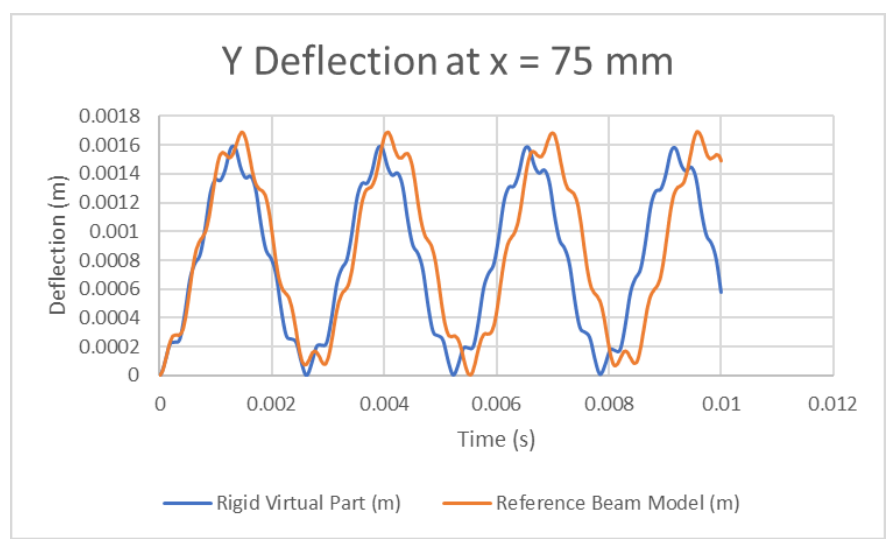

Fig. 12 The bending deflections of the Fixed-Free beam under a bending dynamic force at the middle

\section{Case (e), Harmonic Torsional Force}

A $150 \mathrm{~mm}$ long bar with a circular cress-section and radius $\mathrm{R}=10 \mathrm{~mm}$ is under a harmonic moment $M(t)=10 \operatorname{Sin}(\omega t) \mathrm{Nm}$ at the midpoint location. Therefore, two harmonic sinusoidal dynamic forces $F(t)=500 \operatorname{Sin}(\omega t) N$ as shown in Fig. 13 is creating a couple to make that moment possible. Please keep in mind that the present torsional test case is solved in the frequency domain and not in the time domain.

This problem has been modeled with both the Rigid virtual part and the Rigid Spring virtual part; depicted in Fig. 14. Therefore, the last right $50 \mathrm{~mm}$ of the bar has been replaced by virtual part with a "Handler" point at the centroid of the virtual portion. The rotatory inertia of the virtual portion is also calculated as $\quad J_{V P, \theta y}=\frac{1}{2} m_{V P} R^{2}=\frac{\pi}{2} \rho L_{V P} R^{4}=6.17 E-$ $6 \mathrm{~kg} \cdot \mathrm{m}^{2}$ and added as a lumped mass and a rotational inertia to the virtual parts for both models. In the Rigid Spring case, the torsional stiffness of the bar is given by $k_{V P, \theta y}=\frac{G J}{0.5 L_{V P}}=$ $9.93 E+4 N . m / r a d$ which is then inputted in the dialogue box.

$17^{\text {th }}$ LACCEI International Multi-Conference for Engineering, Education, and Technology: "Industry, Innovation, And Infrastructure for Sustainable Cities and Communities", 24-26 July 2019, Jamaica. 


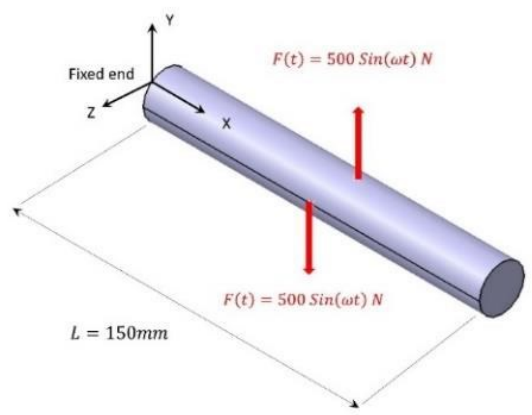

Fig. 13 Fully 3D Model of the Fixed-Free beam under a harmonic moment at the middle point [2]
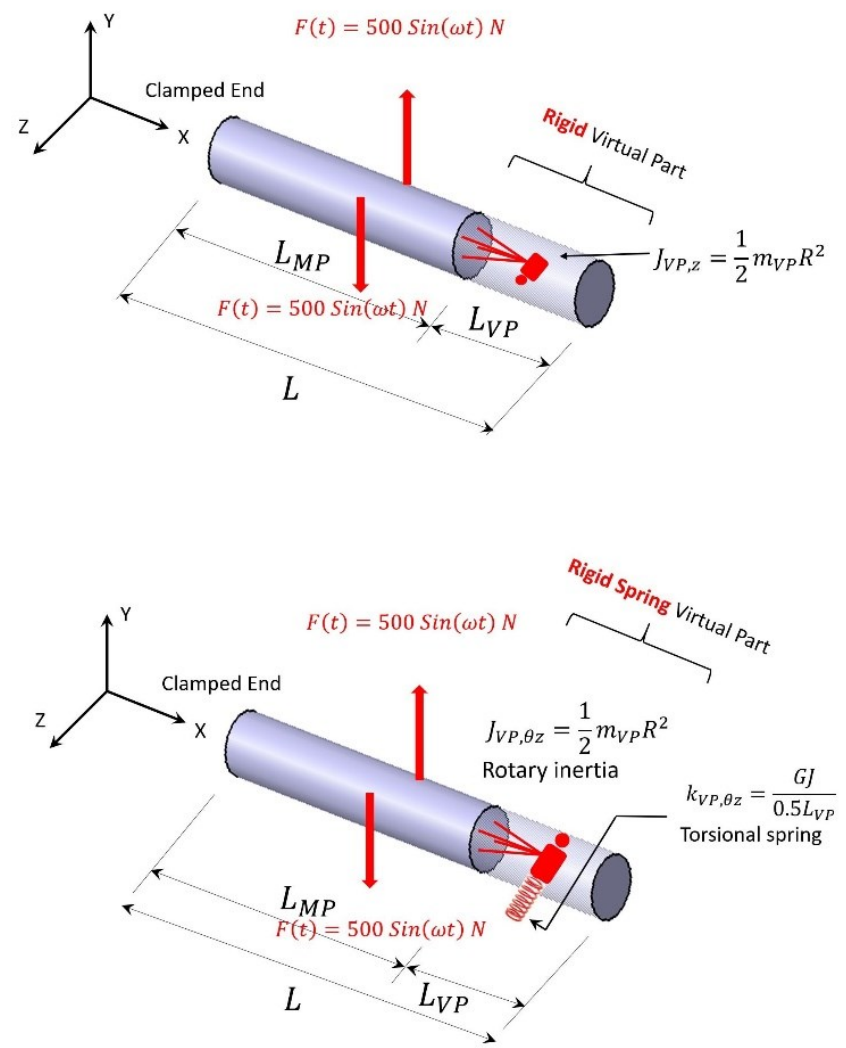

Fig. 14 The Rigid virtual part and the Rigid Spring virtual part models of the Fixed-Free case under a harmonic moment at the middle

Fig. 15 displays the plots of the maximum deflection amplitude as a function of the frequency for the middle point of the bar. As shown, the Rigid virtual part and Rigid Spring Virtual Part are in good agreement for the first peak but diverging from one another for the frequencies larger than $15000 \mathrm{~Hz}$. Although the results have large errors for higher frequency, most structural applications primarily rely on the lower end of the spectrum; well below the $15000 \mathrm{~Hz}$ [2].

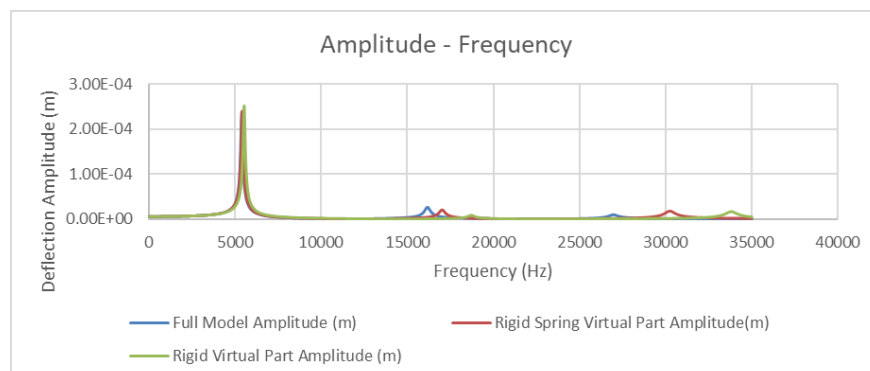

Fig. 15 The deflection amplitude as function of frequency plots for a bar under a harmonic moment at the midpoint location

\section{A BAR UNDER SUDDENLY APPLIED GRAVITY LOADING}

\section{Case (a), Rigid Spring Virtual Part, Axial Gravity}

The problem under consideration is the same as the FixedFree $150 \mathrm{~mm}$ steel bar except that it is subjected to a suddenly applied axial distributed gravity loading. The problem has been modeled with the Rigid Spring virtual part. The left $100 \mathrm{~mm}$ of the bar is modeled with solid tetrahedron elements and the right $50 \mathrm{~mm}$ is a Rigid Spring virtual part with a "Handler" point at the centroid of the virtual portion, displayed in Fig. 16. Notice that as the virtual parts do not recognize the gravity loading directly, a force of $F(t)=m_{v p} g=0.039 * 9.81=0.385 \mathrm{~N}$ is applied on the virtual part to invoke it.

This problem has an analytical solution based on separation of variable method presented in [6] which is used for comparison purposes. In this reference, the axial deflection " $\mathrm{u}(\mathrm{x}, \mathrm{t})$ " of any point at the time " $\mathrm{t}$ " is calculated from the expression below:

$$
\begin{aligned}
& u(x, t)=2 \frac{g \sum_{n=1}^{N} \frac{\sin (\lambda(n) x)}{\lambda(n)^{3}}}{L a^{2}}-2 \frac{g \sum_{n=1}^{N} \cos (a \lambda(n) t) \frac{\sin (\lambda(n) x)}{\lambda(n)^{3}}}{L a^{2}} \\
& \text { Where } \quad \lambda(n)=\frac{(2 n-1) \pi}{2 L} \quad a=\sqrt{\frac{E}{\rho}}
\end{aligned}
$$

The following values are employed,

$$
\begin{aligned}
g & =9.81 \frac{\mathrm{m}}{\mathrm{s}^{2}} & E & =200 E+9 \\
L & =0.15 \mathrm{~m} & \rho & =7860 \frac{\mathrm{kg}}{\mathrm{m}^{3}}
\end{aligned}
$$

The axial displacement as a function of time for the point $100 \mathrm{~mm}$ away from the left point $(\mathrm{x}=100 \mathrm{~mm})$ is calculated using the equation above, considering only the first three modes with the Mathcad software. The same deformation is plotted in Catia for the Rigid Spring virtual part model. Note that the points where $\mathrm{x}=100 \mathrm{~mm}$ are the points on the support face. Both plots are displayed at Fig. 17. The Rigid Spring virtual part results are in a very good agreement with the reference plot [2].

$17^{\text {th }}$ LACCEI International Multi-Conference for Engineering, Education, and Technology: "Industry, Innovation, And Infrastructure for Sustainable Cities and Communities", 24-26 July 2019, Jamaica. 


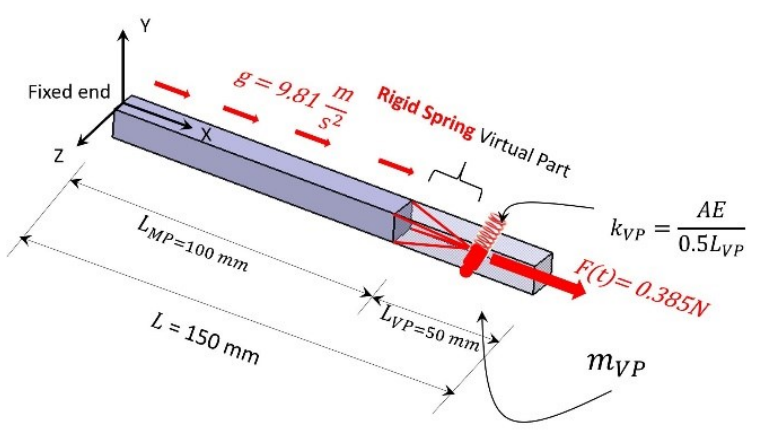

Fig. 16 The Rigid Spring virtual part model of the Fixed-Free case under an axial gravity

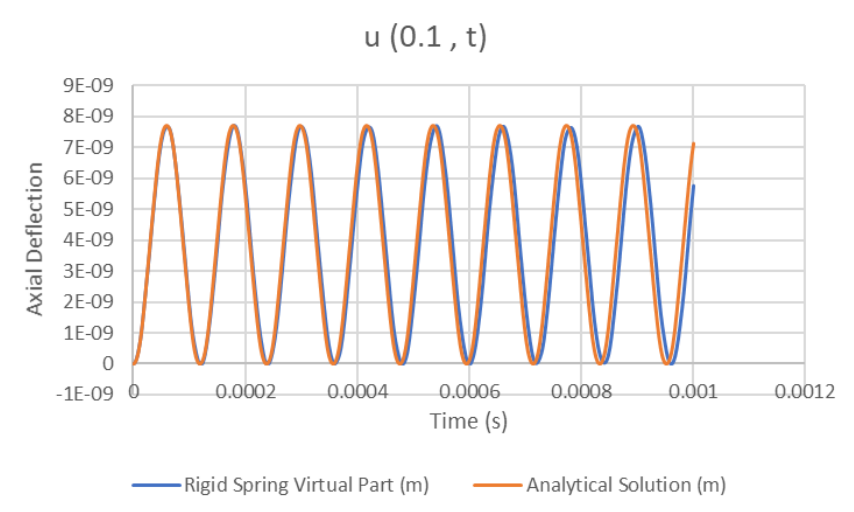

Fig. 17 The axial deflection as a function of time plots for a Fixed-Free bar under an axial gravity

Case (b), Rigid Virtual Part, Axial Gravity

Here, the Rigid virtual part is used for the latter $50 \mathrm{~mm}$ of the bar as depicted in Fig. 18. Therefore, the right $50 \mathrm{~mm}$ of the bar behaves more rigidly than the rest of the bar. It is not reasonable to use the analytical solution form the literature. Therefore, the same reference finite element model using beam elements described earlier, is created and subjected to the same axial gravity in Catia v5 and for comparison purposes. This situation is displayed in Fig 19.

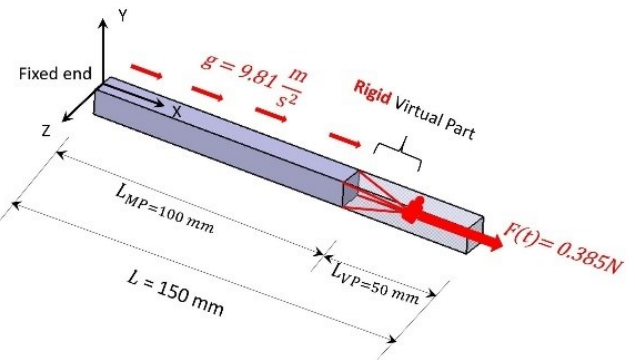

Fig. 18 The Rigid Virtual Part model of the Fixed-Free case under an axial gravity

The axial displacement as a function of time for the point $100 \mathrm{~mm}$ away from the left point $(\mathrm{x}=100 \mathrm{~mm})$ calculated by Catia for both the Rigid virtual part model and the reference beam model is plotted in Fig. 20. Note that the points where $\mathrm{x}=100 \mathrm{~mm}$ are the points at the support face. The Rigid virtual part results are in a perfect agreement with the reference beam model plot.

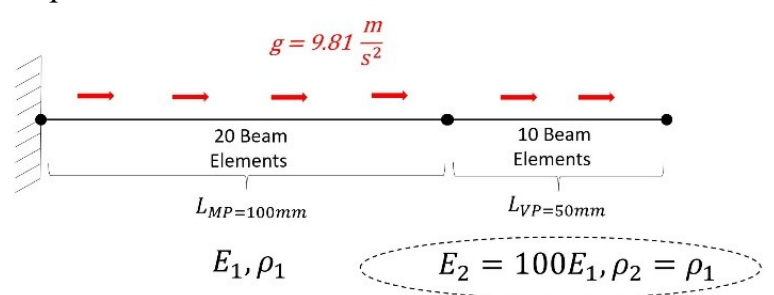

Fig. 19 The reference model for Rigid virtual part model of the bar under suddenly applied gravity loading

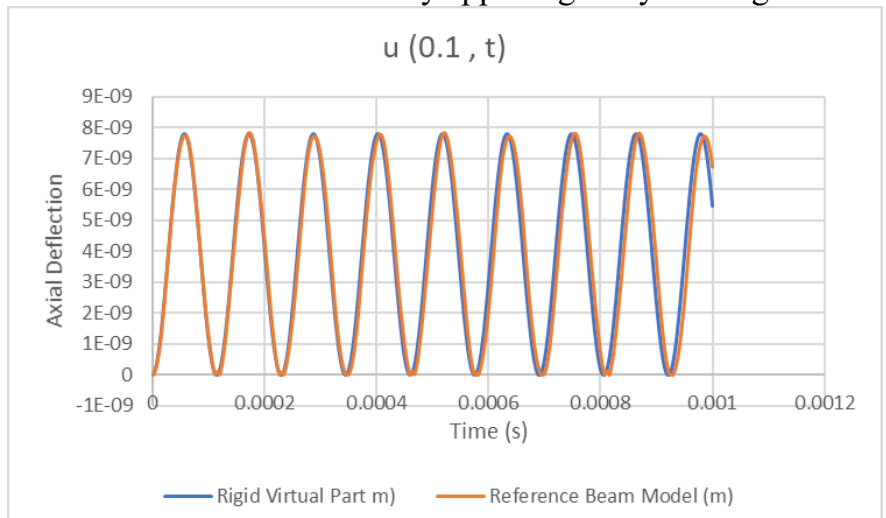

Fig. 20 The axial deflection as a function of time plots for a Fixed-Free bar under an axial gravity

\section{A PLATFORM UNDER HARMONIC DYNAMIC LOAD}

The platform shown in Fig. 21 is subjected to an unbalanced rotating machine applying a harmonic sinusoidal load of amplitude $1000 \mathrm{~N}$ [7]. The platform consists of a $1 \mathrm{~m}$ $\times 1 \mathrm{~m}$ square plate with a thickness of $0.01 \mathrm{~m}$ standing on four $0.5 \mathrm{~m}$ long legs. The legs also have a $0.01 \mathrm{~m} \times 0.01 \mathrm{~m}$ square cross sections. The bottom faces of the legs are assumed to be clamped. Instead of modeling the rotating machine, a Rigid virtual part is considered with a "Handler" point at the middle of the platform but $0.5 \mathrm{~m}$ above it. The support face of the virtual part is $0.1 \mathrm{~m} \times 0.1 \mathrm{~m}$ square in the middle of the platform. The structure is entirely made of steel. The problem is modeled utilizing shell and beam elements displayed in Fig. 22. The platform is modeled with $3 \mathrm{~mm}$ parabolic Octree Triangle shell elements and $10 \mathrm{~mm}$ thick $2 \mathrm{D}$ property. These are the exact terminologies from Catia v5. The legs are meshed with $3 \mathrm{~mm}$ linear beam elements with square cross section 1D properties. Each leg is connected to the platform by defining a Rigid Connection between its top vertex and the corner vertex of the platform. In order to make the support face for the virtual part in the middle of the platform, one can make two separate patches and connect them with a Fastened Connection. In fact, the plate is modeled with a $0.1 \mathrm{~m} \times 0.1 \mathrm{~m}$ square cavity at its middle and a separate $0.1 \mathrm{~m} \times 0.1 \mathrm{~m}$ patch is modeled at the

$17^{\text {th }}$ LACCEI International Multi-Conference for Engineering, Education, and Technology: "Industry, Innovation, And Infrastructure for Sustainable Cities and Communities", 24-26 July 2019, Jamaica. 
middle and is fastened to the main platform. This connection is shown in Fig. 22 with a "fastened" sign.

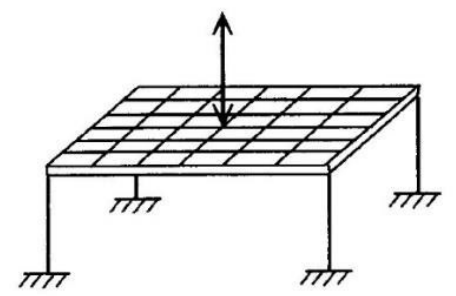

Fig. 21The Platform under a sinusoidal force [7]

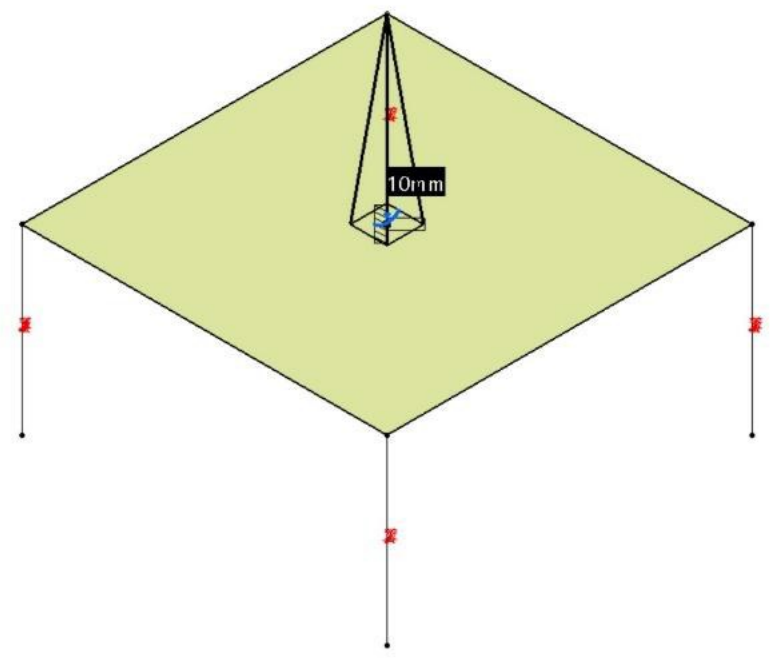

Fig. 22 The shell-beam Catia FE model of the platform under harmonic response [2]

In order to assess the quality and accuracy of the shell-beam calculation, a fully three-dimensional model of the platform was also created, displayed in Fig. 23. Therefore, the model is created in the Part Design workbench and meshed with $5 \mathrm{~mm}$ Parabolic Octree Tetrahedron solid mesh. A smaller local mesh size is used in the critical areas. Hence, a local mesh size of 3 $\mathrm{mm}$ has been applied for the four clamped bottom faces of the legs and the highlighted edges displayed in red. Furthermore, a zoomed view of the local mesh at a corner of the platform is displayed in Fig. 24 to clarify the differences between the adjacent element sizes. The strategy to make the support face is to create the $0.01 \mathrm{~m} \times 0.01 \mathrm{~m}$ square surface at the middle and "sew" it to the part in Wireframe and Surface Design workbench. In the language of Catia software, this develops a "feature" in the solid model for our purpose. Hence, this area can be used as the support face of the virtual part.

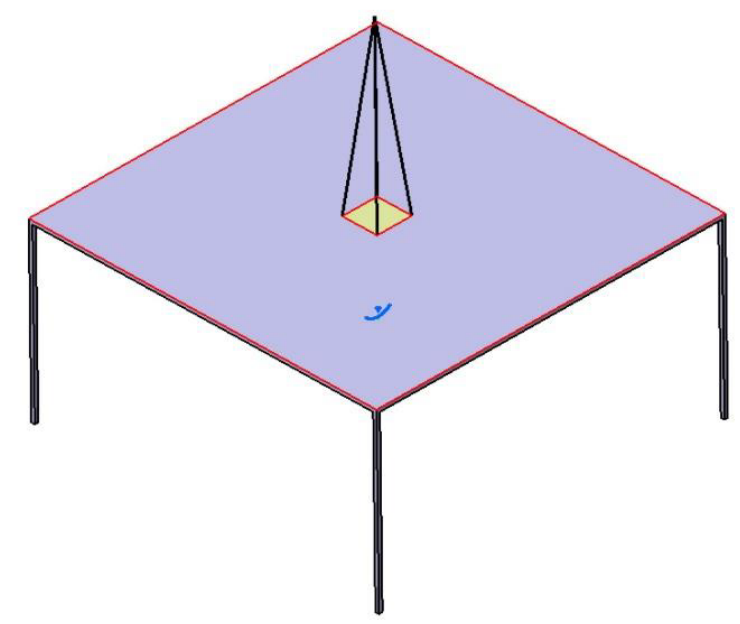

Fig. 23 The highlighted edges for local mesh for the solid model of the platform under harmonic response [2]

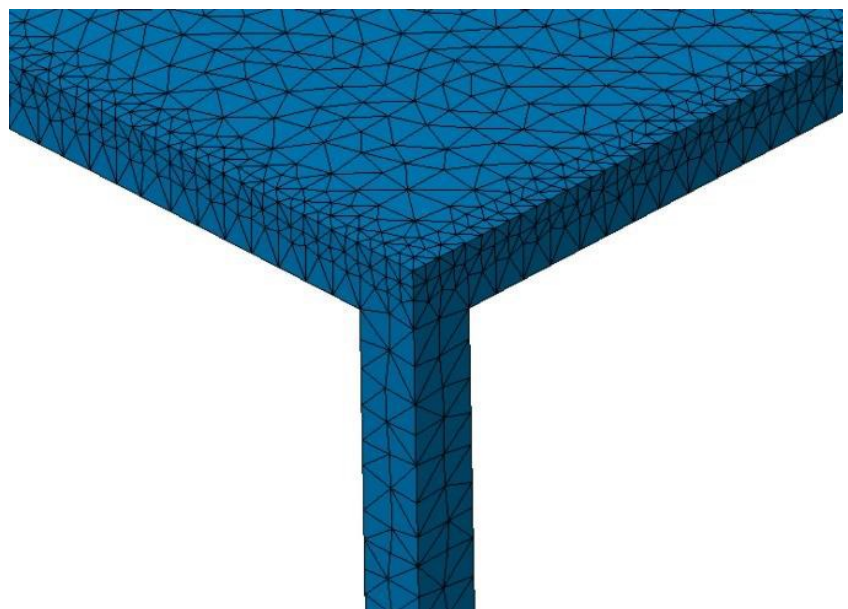

Fig. 24 A zoomed view of the local mesh of the solid Catia

FE model of the platform under harmonic response [2]

As mentioned earlier, Catia uses modal superposition technique to solve dynamic problems. Therefore, the next step is to consider the natural frequencies of the system. The first ten natural frequencies are used for further analysis based on the modal participation report from Catia for the beam-shell model. This statement is based on the common practice of using approximately $80 \%$ modal mass participation factor for truncation purposes. The next step is to conduct a Harmonic Dynamic Response Case. Hence, a load with amplitude of 1000 $\mathrm{N}$ on the vertical direction is applied on the Rigid virtual part with $1 \%$ modal damping. The "Harmonic Dynamic Response Solution" module with 200 steps from $0 \mathrm{~Hz}$ to $200 \mathrm{~Hz}$ is considered and the Frequency Response Curve for the vertical deflection for a corner point of the platform is plotted for both models which is presented in Fig. 25. Both the mode shapes and amplitudes are in a good agreement, particularly, for the frequencies smaller than $100 \mathrm{~Hz}$. This practical example which is a very common scenario shows the advantages of using a

$17^{\text {th }}$ LACCEI International Multi-Conference for Engineering, Education, and Technology: "Industry, Innovation, And Infrastructure for Sustainable Cities and Communities", 24-26 July 2019, Jamaica. 
Rigid virtual part to model a rotating motor for apply harmonic load on a steel platform [2].

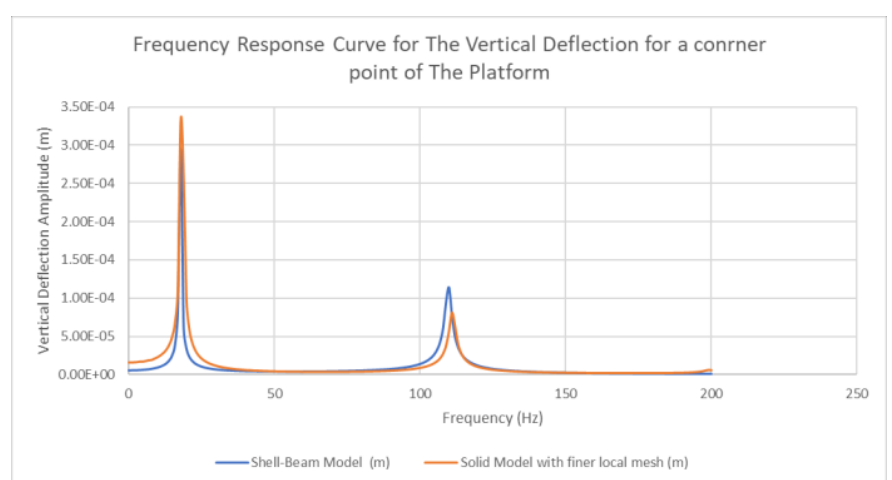

Fig. 25 Frequency Response Curve for The Vertical Deflection for a Corner Point of The Platform under harmonic response [2]

\section{BASICS OF MODAL SUPERPOSITION}

Since the concept of modal superposition is the fundamental building block of linear dynamics, presenting a brief description of the topic is warranted [8], [9].

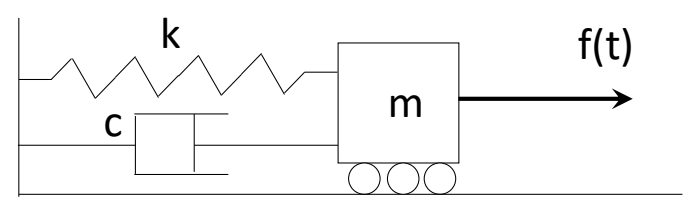

Fig. 26 Single Degree of Freedom, Mass-Spring-Damper System

The equation of motion describing the above system is given by the well-known second order linear differential equation below. $m \ddot{x}+c \dot{x}+k x=f(t)$

Very often this equation is written in the canonical form

$\ddot{x}+2 \xi \omega_{n} \dot{x}+\omega_{n}^{2} x=\frac{f(t)}{m}$

Here, $\xi=\frac{c}{c_{c r}}=\frac{c}{2 \sqrt{k m}}$ is the damping ratio and $\omega_{n}=\sqrt{\frac{k}{m}}$ is the undamped natural frequency of the system, The damped natural frequency is given by $\omega_{d}=\omega_{n} \sqrt{1-\xi^{2}}$. Assuming the zero initial conditions (zero displacement and velocity), the solution to the above equation can be written using the Duhamel integral as (also known as the convolution integral),

$x(t)=\int_{0}^{t} f(\tau) h(t-\tau) d \tau$

The function $h(t)$ is known as the damped impulse response function and given by $h(t)=\frac{1}{m \omega_{d}} e^{-\xi \omega_{n} t} \sin \omega_{d} t$

Therefore, if the impulse response function is available (and it is in this problem), one knows everything about a linear single degree of freedom system.

When dealing with a distributed parameter system (i.e. a continuum), there are infinite number of modes. Using the finite element analysis, this is reduced to a finite number of modes and therefore a multi-degree of freedom system is created. The equation of motion for a multi-degree of freedom system is written as

$[M]\{\ddot{x}\}+[C]\{\dot{x}\}+[K]\{x\}=\{F\}$

The only difference with a SDOF system is that the mass, damping, and stiffness are matrices and $\{x\}$ is the displacement vector. Now using the modal coordinates (eigenvectors of $[M]^{-1}[K]$ ) one can decouple the above system of equations so that each takes the form of non-dimensional SDOF system. These can be solved using the Duhamel integral and reconstructed to arrive at $\{x(t)\}$.

Note that there is another issue involved in carrying the rest of the calculation. There may be no need to include all the modes of the structure. This means that the transient (dynamic) response may be dominated by the few smaller frequencies. This is generally the case with structural dynamics problems. The more systematic way to decide how many modes (and which ones) to be included is the calculation of the modal participation factors. A rule of thumb is to include modes which end up contributing to $80 \%$ of the total mass.

\section{CONCLUDING REMARKS}

This paper presents the reader with several examples dealing with the usage of Virtual Parts in linear dynamics implementation within Catia v5. The first four examples are classical components whereas the last one is of a more practical nature. In all the examples considered, the Catia generated results are either compared with the exact analytical solution, or with the 3D/Beam FEA model where no Virtual Parts were utilized. In general, there are excellent agreements between the two. The use of the Virtual Part functionality substantially reduces the computer resource requirements yet produces reasonably accurate results. As indicated earlier in the paper, the metric for computational cost is assumed to be the number of elements needed for the "full" model. This is probably grossly simplifying the overall factors associated with the cost of computation. In view of the comments on the modal participation factor, very few modes were selected to carry out the dynamic calculations. Having said that, one should exercise care and use engineering intuitions for making such choices.

$17^{\text {th }}$ LACCEI International Multi-Conference for Engineering, Education, and Technology: "Industry, Innovation, And Infrastructure for Sustainable Cities and Communities", 24-26 July 2019, Jamaica. 


\section{ACKNOWLEDGMENT}

The authors gratefully acknowledge the support of the Faculty of Engineering at the University of Windsor under the internal grant 809153 .

\section{REFERENCES}

[1] Zamani N.G., The Challenges of Teaching Finite Element Analysis in the Undergraduate Curriculum, LACCEI Conference, San Jose, Costa Rica, p. 1-10., 2016.

[2] Ramezani H., (2018), The Virtual Part Functionalities in Catia V5, Finite Element Aspects (Master's thesis). University of Windsor.

[3] Zamani, N.G., A Pedagogy of the Concept of a Load at a Distance in FEA codes (Basic Case Studies). International Conference of Materials to Design, M2D2017, Algarve, Portugal, June 2017.

[4] Zamani N G, Ramezani H, Modal Calculations Using the Rigid Virtual Part in the Catia v5 ${ }^{\text {TM }}$ Finite Element Software, 16th LACCEI International Multi-Conference for Engineering, Education, and Technology: "Innovation in Education and Inclusion", 19-21 July 2018, Lima, Peru.

[5] Asier Ruiz de Aguirre Malaxetxebarria, HOW RBE1 RBE2 AND RBE3 WORK, 26/04/2014, AERSYS-7015, AERSYS KNOWLEDGE UNIT.

[6] Georgi P. Tolstov, Fourier Series, translated by Richard A. Silverman, Dover Publications, 1976.

[7] Zamani N G, Altenhof W J, Introduction to the Finite Element Analysis, FEA Connection, 2007.

[8] Inman, D.J., Engineering Vibrations, $4^{\text {th }}$ Edition, Pearson Publishing. 2014.

[9] Palm III, W.J., Mechanical Vibrations, Wiley Press, 2006.

$17^{\text {th }}$ LACCEI International Multi-Conference for Engineering, Education, and Technology: "Industry, Innovation, And Infrastructure for Sustainable Cities and Communities", 24-26 July 2019, Jamaica. 